\title{
DETECTION OF AFLATOXIN B1 IN CHICKEN AND QUAIL LIVERS IN MOSUL CITY
}

\author{
H.S. AL-NAEMI*; M.G. HASSAN*; S.A. AL-JUHAISHY** and A.M. SHAREEF* \\ *: Department of veterinary public health, College of Veterinary Medicine, University of Mosul, Mosul, Iraq. \\ :* State Board for Agricultural Researches, Mosul, Iraq.
}

Email: montaha2007montaha@yahoo.com

\section{ABSTRACT}

Received at: $28 / 10 / 2013$

Seventy eight liver samples were collected during spring season (April to June/ 2013), from different meat markets in Mosul city, distributed into 3 liver poultry types, 26 for each of quail, local broiler and imported broiler liver samples for

Accepted: 19/12/2013 estimation of liver residual AFB1 concentrations using competitive enzyme immunoassay ELISA kit. Results revealed that all tested quail livers (100\%) were positive for residual AFB1, followed by livers of imported broilers (92.30\%), while in the third order were those belonged to the local broilers $(80.76 \%)$, with mean values of $2.280,1.024$ and $0.885 \mathrm{ppb}$ respectively. The significance of residual AFB1 of poultry livers on human health was discussed.

Key words: Aflatoxin B1, Chicken, Mosul City.

\section{INTRODUCTION}

Out of the more than 300 mycotoxins discovered, aflatoxins (AFs) as a toxic secondary metabolites produced by Aspergillus fungus growing in susceptible agricultural commodities are of major concerns. FAO has estimated that up to $25 \%$ of the world's food crops and a higher percentage of the world's animal feedstuffs are significantly contaminated by mycotoxins. Here in Iraq, outbreaks of Aflatoxicosis had been reported in broiler farms (AL-Sadi et al., 2000) and variable amount of aflatoxins were actually reported in commercial broiler feeds (Shareef, 2004).

AFs can result in major economic losses and can negatively affect animal and human health after their consumption even at very low concentration. AFs may cause serious health problems, since they are mutagenic, carcinogenic, teratogenic and immunosuppressive compounds (Razzaghi-Abyaneh, 2013).

Apart from their toxicological effects in affected animals, the carry-over through animal derived products, such as meat, milk and eggs into the human is an important issue. So when focusing on how mycotoxins play a role in food safety, attention should be limited to mycotoxins like aflatoxins that are known to be transferred from feed to food of animal origin, as this food represents a significant route of exposure for humans (FAO and IFIF, 2010).

When AF ingested by animals, it is readily absorbed via the gastrointestinal tract into the portal blood and is carried to the liver where it is metabolized. Aflatoxin residues in meat are uncommon and rarely found (Biswas et al., 2010). However, its more common in organs especially liver (Wyatt et al., 1973). In the liver cells AFB1 is converted to classes of metabolites that may be transmitted to edible animal products through the food chains which considered an important aspect of mycotoxin contamination (Hussein and Brasel, 2001).

Dietary contamination of aflatoxins pose a big risk to human health including acute aflatoxicosis, hepatocellular carcinoma, hepatitis B virus infection, growth impairment in different regions of the World particularly Asian and African countries (Wild and Gong, 2010). Frequent analytical surveillance program by food control agencies is highly recommended to control the incidence of aflatoxins contamination in food grains to ensure food safety and to protect consumers health. Some analytical techniques such as thin-layer chromatography, (TLC), high performance liquid chromatography (HPLC) (Bacaloni et al., 2008), two-dimensional thin layer chromatography and enzyme-linked immunosorbent assay (ELISA) have been available for the qualitative and quantitative analysis of AFs. ELISA has a good sensitivity, speed and simplicity, and it is the most used immunoassays in food-aflatoxin detection. (Lamberti et al., 2009; Reddy et al., 2011).

In Mosul City no ELISA survey is available about the natural amounts of residual AFB1 in poultry livers retailed in local meat markets, and for this reason this work was done. 


\section{MATERIALS and METHODS}

\section{Sampling:}

Seventy eight liver samples were collected during spring season (April to June 2013), from different meat markets in Mosul city (Al-Rashidia, ALhamdania and meat retail markets in city center), distributed in 3 categories, 26 for each (quail liver samples, local broiler liver samples and imported broiler liver samples). Samples were transferred to the laboratory of the department of Veterinary Public Health, College of Veterinary Medicine, University of Mosul. All samples were stored at $-20{ }^{\circ} \mathrm{C}$ till analysis.

\section{Estimation of liver residual AFB1 concentrations:}

Levels of residual AFB1 concentrations in poultry liver samples were estimated using ELISA kit (Shenzhen Lvshiyuan Biotechnology Co., Ltd, Version: 2011-1.China). The test kit is based on the competitive enzyme immunoassay for the detection of AFB1 in liver. The coupling antigen is pre-coated on the micro-well stripes. The AFB1 in the sample and the coupling antigens on the micro-well stripes compete for the anti-AFB1 antibodies. After the addition of the enzyme conjugate, the TMB substrate is added for coloration. The optical density (OD) value of the samples has a negative correlation with the AFB1 in the sample. This value is compared to the standard curve and the AFB1 residues is subsequently obtained. The procedure is simply as follows: Two $\pm 0.05 \mathrm{gm}$ of homogenized liver samples were transferred to $50 \mathrm{ml}$ centrifuge tube and then shaked thoroughly for 30 s with $8 \mathrm{ml}$ sample extract solution (3 parts of methanol dissolved with 2 parts of deionized water), at above $4000 \mathrm{r} / \mathrm{min}$ at $15^{\circ} \mathrm{C}$ for $10 \mathrm{~min}$. After centrifugation, to $100 \mu \mathrm{l}$ of the supernatant $500 \mu \mathrm{l}$ of redissolving solution were added (prepared by dissolving one part of the concentrated redissolving solution, already offered by the kit, with one part of deionized water) and shaked thoroughly. After completion, $50 \mu \mathrm{l}$ were used for testing AFB1 residual concentrations.

\section{RESULTS}

From figure (1), it is evident that the number and percentage of AFB1 contamination in livers of the quail, imported broilers and local broilers, were all 26 tested livers $(100 \%)$ for quails were positive. In the second order were livers of imported broilers, in which 24 livers were positives and only two were negative to the presence of AFB1 with a percentage of $(92.30 \%)$. In the third order were those belonged to the local broilers, which were positive in 21 tested livers and 5 negative to AFB1 residue with a percentage of $(80.76 \%)$.

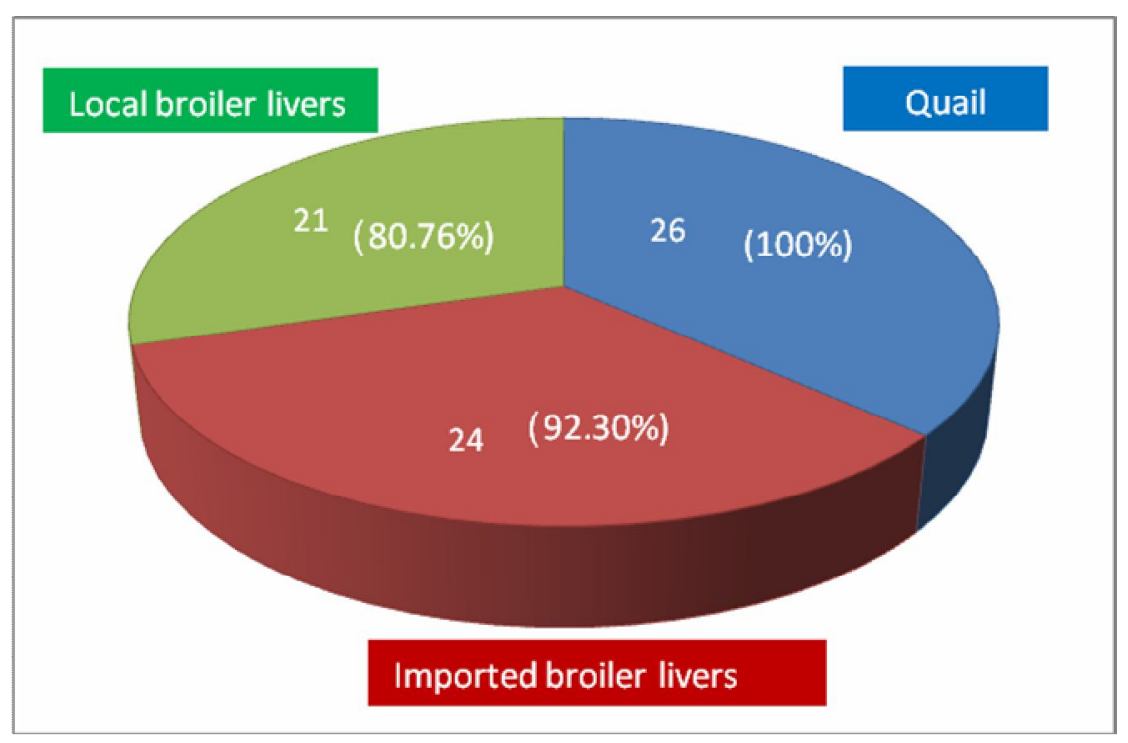

Figure 1: Number and percentage of the positive livers for AFB1 residues in quail, local and imported broiler livers out of 26 livers tested for each poultry type.

The higher positive number and percentage of residual AFB1 were in quail livers, also were had a significant $(\mathrm{p}<0.05)$ higher residual AFB1 concentrations $(2.280 \mathrm{ppb})$ than those of the local and imported broiler livers. Although the positive number and percentage of AFB1 residues recorded in imported broiler livers were higher than those of the local ones, but they contained lesser AFB1 residual quantities $(0.885 \mathrm{ppb})$ compared with the local ones $(1.024 \mathrm{ppb})$, but they still not significantly different $(\mathrm{p}<0.05)$ (Table 1$)$. 
Table 1: Range and mean concentrations (ppb) of AFB1 in Quail, Local broiler and Imported broiler livers.

\begin{tabular}{cccc}
\hline $\begin{array}{c}\text { Type of examined liver } \\
\text { samples }\end{array}$ & $\begin{array}{c}\text { No. of examined liver } \\
\text { samples }\end{array}$ & Range & Mean \pm SE \\
\hline Quail & 26 & $0.730-4.290$ & $2.280 \pm 0.207$ \\
& 26 & $0.000-1.970$ & $1.024 \pm 0.128$ \\
Local broiler & 26 & $0.000-3.850$ & $\mathrm{~B}$ \\
\hline Imported broiler & & & $0.885 \pm 0.207$ \\
& & & $\mathrm{~B}$ \\
\hline
\end{tabular}

Different letters are significantly different at $(\mathrm{p}<0.05)$.

\section{DISCUSSION}

Liver of animal origin is one of the meat component widely and lovely used for consumption among Mosul citizens, so it is highly prized. It contains high biological value protein and important micronutrients that are needed for good health throughout life. Residues of aflatoxins and their metabolites could be present in the meat and liver of poultry receiving aflatoxin contaminated feeds, that could pose a risk to human health (Bintvihok and Davitiyananda, 2002). When chicken fed AFB1 with contaminated rations, AFB1, AFM1, and aflatoxicol have been detected in liver, kidneys and thigh muscles. Besides these, AFB2a has also been detected in livers of both broilers and layers on a ration contaminated with a mixture of aflatoxins (Razzaghi-Abyaneh, 2013). When our findings of the residual AFB1 in tested poultry livers come to be compared with the maximum tolerable levels of AFB1 in human foodstuffs the picture would have both controversial decisions, either being passed or not. The reason is that all the concentrations obtained in our study were $<5 \mathrm{ppb}$ which were above or below the different regulations undertaken by different countries regarding the maximum tolerated residual AFB1 in human foodstuffs. Regulations for major mycotoxins in commodities and food exist in at least 100 countries, most of which are for aflatoxins, maximum tolerated levels differ greatly among countries. They are $0 \mathrm{ppb}$ in Poland, Rumania and Singapore; $1 \mathrm{ppb}$ in Switzerland; 5 ppb in Hungary, the Netherlands and Zimbabwe; $10 \mathrm{ppb}$ in France and Japan; $20 \mathrm{ppb}$ in Nigeria and Portugal and $30 \mathrm{ppb}$ in India. So our results of tested livers were above the limits in Poland, Rumania, Singapore and Switzerland, but under those in Hungary, the Netherlands, Zimbabwe, France, Japan, Nigeria, Portugal and India. Moreover, our results were also under the limits of the European Commission Regulation 2010/165/EC which established limits of 8 and $15 \mu \mathrm{g} / \mathrm{kg}(\mathrm{ppb})$ for AFB1 and total AFs respectively as a maximum level of aflatoxins in food allowed to ensure food's safety (Agag, 2004; Razzaghi-Abyaneh, 2013). Here in Iraq it had not yet been decided the maximum tolerable limits of aflatoxins both in feeds or foods.

The suspected dietary aflatoxin contamination level in flocks from which our tested livers had been gained may occur between 250-5000 ppb, depending on the result offered by (Bintvihok and Davitiyananda, 2002; Yunus, 2011), who declared that the turnover of aflatoxin in broilers fed aflatoxin at a level of 250-3310 ppb in ration was vary from no detection to $3.0 \mathrm{ppb}$ residual AFB1 in their liver. Anyhow the variations of the $\mathrm{AF}$ residual concentrations in our samples suggested that these levels might be influenced by different factors including dietary AF levels, duration of administration, age, type of the birds and withdrawal of dietary AF from the feeds (Hussain et al., 2010). The outstanding feature of our results was the higher residual AFB1 in local products (quail and local broiler livers) against imported broiler livers which could indicate the lower hygienic measures taken in our domestic poultry production system. The main drawbacks in rearing poultry here in our country especially those concerning mycotoxins, are the absence of regular feed examination for their mycotoxin content in both local or imported feed commodities, poor fungal controlling programs in feeds and feed ingredients, irregular applying of effective mycotoxin adsorbents, no withdrawal period of feeds before sending birds to slaughterhouse and ignoring post-harvest local and imported meat or meat products examination for their mycotoxins content. Regarding imported foodstuffs, best precautions are taken in foreigner countries, among these measures are Hazard Analysis and Critical Control Point (HACCP) application concerning mycotoxins contamination of feeds during poultry production and food products during poultry processing. 
In our country, there is no regulatory limits on AFB1 levels of poultry feed and poultry products and secondary exposure to aflatoxins through consumption of chicken liver and meat derived from the poultry fed AF contaminated feed may pose a risk to consumers health that should be lowered to as low as reasonably achievable because aflatoxins are genotoxic and carcinogenic (Micco et al., 1988; Reddy et al., 2011).

The solution of mycotoxin problem in our foodstuff product should begin from avoiding aflatoxin problem in food grains by drying seeds to the required moisture content immediately after harvest with proper storage structures by spraying fungicides or some other chemicals to reduce Aspergilli and subsequent toxin accumulation on food grains under storage conditions, since there are deficiencies in storage, handling and harvesting in our rearing system.

Moreover optimal postharvest storage conditions will minimize consumer exposure to AFs, and decontamination procedures are strongly needed in most cases since mycotoxin residues in poultry products tend to decrease rapidly after removal of the contaminated diet, which allows "to clean" broilers when feeding a diet free of mycotoxins few days before slaughter coincide with the reducing the bioavailability of aflatoxins using clay and chemoprotection by using adsorbents which inhibit intestinal absorption of mycotoxins in an attempt to alleviate the negative and deleterious effects in poultry production. One approach to managing the risks associated with $\mathrm{AF}$ contamination is use of an integrated system based on the (HACCP) approach. This approach involves strategies for prevention, control, good manufacturing practices, and quality control at all stages of production, from the field to the final consumer (Reddy et al., 2009; Shuaib, 2010).

\section{REFERENCES}

Agag, B.I. (2004): Mycotoxins in foods and feeds. 1Aflatoxins review article. Univ. Bull. Environ. Res. 7, 1: 173-206.

AL-Sadi, H.I.; Shareef, A.M. and AL-Attar, M.Y. (2000): Outbreak of aflatoxicosis in broilers. Iraqi J. Vet. Sci. 13: 93-105

Bacaloni, A.; Cavaliere, C.; Cucci, F. and Patrizia, F. (2008): Determination of aflatoxins in hazelnuts by various sample preparation methods and liquid chromatography-tandem mass spectrometry. J. Chromatography A. 1179, 2: 182-189.

Bintvihok, A. and Davitiyananda, D. (2002): Aflatoxins and their metabolites residues in chicken tissues from 5 parts (10 provinces) of Thailand. Thai. J. Hlth. Res.16, 1: 37-50.
Biswas, A.K.; Kondaiah, N.; Anjaneyulu, A.S.R. and Mandal, P.K. (2010): Food safety concerns of pesticides, veterinary drug residues and mycotoxins in meat and meat products. Asian J. Anim. Sci. 4: 46-55.

FAO (Food and Agriculture Organization) and IFIF (International Feed Indurtry Federation) (2010): Good practices of the feed industry implementing the Codex Alimentarius Code of Practice in Good Animal Feeding. FAO Animal production and Health Manual n.9. Rome. Section 1. Health Hazards associated with animal feed.

Hussain, Z.; Khan, M.Z.; Khan, A.; Javed, I.; Saleemi, M.K.; Mahmood, S. and Asi, M.R. (2010): Residues of aflatoxin B1 in broiler meat: Effect of age and dietary aflatoxin B1 levels. Food and Chemical Toxicol. 48: 33043307.

Hussein, H.S. and Brasel J.M. (2001): Toxicity, metabolism, and impact of mycotoxins on humans and animals. Toxicology 167, 2: 101134.

Lamberti, I.; Tanzarella, C.; Solinas, I.; Padula, C. and Mosiello, L. (2009): An antibody based microarray assay for the simultaneous detection of aflatoxin B1 and fumonisin B1. Mycotoxin Res. 25, 4: 193-200.

Micco, C.; Miraglia, M.; Onori, R.; Brera, C.; Mantovani, A.; Ioppolo, A. and Stasolla, D. (1988): Long-term administration of low doses of mycotoxins to poultry. 1. Residues of aflatoxin B1 and its metabolites in broilers and laying hens. J. Food Addit. and Contam. 5: 303-308.

Razzaghi-Abyaneh, M. (2013): Aflatoxins - recent advances and future prospects In Tech Janeza Trdine 9, 51000 Rijeka, Croatia.

Reddy, K.R.N.; Abbas, H.K.; Abel, C.A.; Shier, W.T.; Oliveira, C.A.F. and Raghavender, C.R. (2009): Mycotoxin contamination of commercially important agricultural commodities. Toxin Rev. 28, 2-3: 154-168.

Reddy, K.R.N.; Raghavender, C.R.; Salleh, B.; Reddy, C.S. and Reddy, B.N. (2011): Potential of aflatoxin B1 production by Aspergillus flavus strains on commercially important food grains. Int. J. Food Sci. Technol. 46, 1:161165.

Shareef, A.M. (2004): Incidence of aflatoxins in broiler mixed feeds in Nineveh governorate. Iraqi J. Vet. Sci. 18: 131-138.

Shuaib, F.M.B.; Ehiri, J.; Abdullahi, A.; Williams, J.H. and Jolly, P.E. (2010): Reproductive health effects of aflatoxins: A review of the literature. Reproductive Toxicol. 29: 262-270.

Wild, C.P. and Gong, Y.Y.O. (2010): Mycotoxins and human disease: a largely ignored global health issue. Carcinogenesis. 31(1): 71-82. 
Wyatt, R.D.; Briggs, D.M. and Hamilton, P.B. (1973): The Effect of dietary aflatoxin on mature broiler breeder males. Poult. Sci. 52, 3: 1119-23.
Yunus, A.W.; Razzazi-Fazeli, E. and Bohm, J. (2011): Aflatoxin B1 in Affecting Broiler's Performance, Immunity and Gastrointestinal Tract: A Review of istory and Contemporary Issues. Toxins. 3: 566-590.

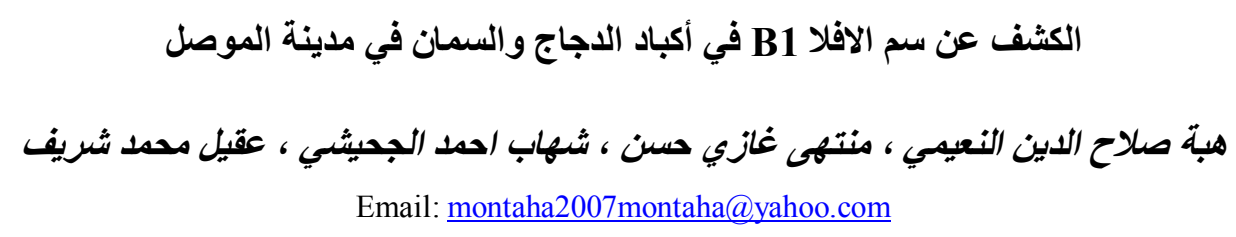

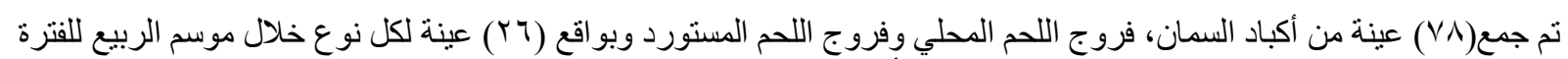

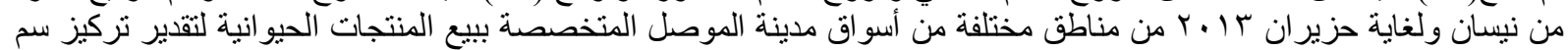

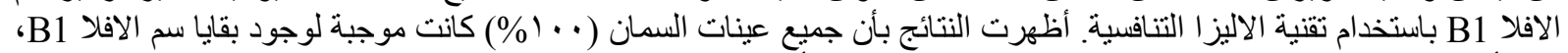

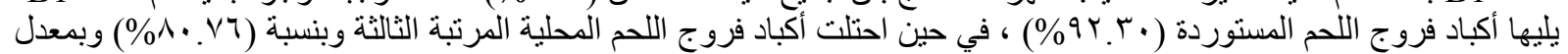

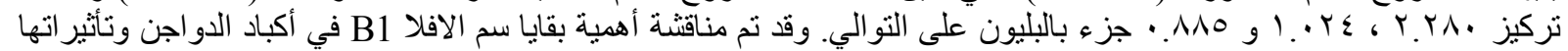
السمية على الصحة العامة للمستهلكين. 